\title{
Thermoluminescent properties of Dy doped calcium borate based glass for dose measurement subjected to photon irradiation
}

\author{
H. A. Tajuddin ${ }^{1}$, W. M. S. WanHassan ${ }^{1}, S . F .$, Abdul Sani ${ }^{2}$, Nurul Syazlin Shaharin ${ }^{l}$ \\ ${ }^{1}$ Department of Physics, Faculty of Science, Universiti Teknologi Malaysia, 81310 UTM Johor \\ Bahru, Johor Darul Takzim, Malaysia. \\ ${ }^{2}$ Department of Physics, University of Malaya, 50603 Kuala Lumpur, Malaysia.
}

\begin{abstract}
This study presents the thermoluminescent (TL) dosimetric properties of calcium borate glass with various dopant concentration of dysprosium (Dy). Calcium borate glass is a new potential material to be used in radiation measurement with absorption coefficient that is close to human bone. A series of glasses based on chemical equation $x \mathrm{CaO}-(100-x) \mathrm{B}_{2} \mathrm{O}_{3}$ system, $x=0.1,0.2,0.3,0.4,0.5(0 \leq x \leq 100)$ $\%$ weight have been prepared by melt quenching method. The X-ray diffraction analysis of glass samples were carried out and the result showed a broad peak, which confirmed the amorphous nature of the glass. The $70 \mathrm{~B}_{2} \mathrm{O}_{3}-30 \mathrm{CaO}$ glass sample was found as the most stable among other glass samples studied. Present work focuses on $70 \mathrm{~B}_{2} \mathrm{O}_{3}-30 \mathrm{CaO}$ glass of $(0.01-0.4) \mathrm{mol} \%$ Dy-doped in order to investigate the thermoluminescence (TL) properties, in particular, dose-response and fading. The glass samples were irradiated to dose range of 0.5-4.0 Gy subjected to 6MV photon irradiations of LINAC Primus MLC 3339. TL response of $0.3 \mathrm{~mol} \%$ Dy-doped $70 \mathrm{~B}_{2} \mathrm{O}_{3}-30 \mathrm{CaO}$ glass was found to produce highest response, with good linear doseresponse relationship.
\end{abstract}

Keywords: Thermoluminescence, Borate glass, Dopant, Dysprosium, Photon irradiation.

\section{Introduction}

Since 1950s there have been extensive research on thermoluminescence dosimeter (TLD) and its application in radiation dosimetry. These include $\mathrm{LiF}$ and $\mathrm{CaF}_{2}$, the sulphates groups $\mathrm{MgSO}_{4}, \mathrm{CaSO}_{4}$ and $\mathrm{BaSO}_{4}$, and the oxides group $\mathrm{AL}_{2} \mathrm{O}_{3}, \mathrm{BeO}$ and $\mathrm{SiO}_{2}$. A current highly popular medium for radiation dosimetry are the phosphor-based thermoluminescent dosimetry (TLD) family, of which Li:Mg,F,Ti is perhaps the most well known. Problems arise when such TLDs are used for radiation dose evaluations in radiotherapy and environmental monitoring, not least because of their relatively large dimensions (typically *Corresponding author: hamizaahmadtajuddin@gmail.com 
some several $\mathrm{mm}$ and more) and hygroscopic nature, the latter certainly limiting their versatility. Borate glass compounds have found to be advantageous materials for solving these problems and widely investigated for radiation dosimetry application [1]. It was recognised that pure borate also known as alkali borate glasses have attractive interest as thermoluminescence (TL) dosimeter material, providing the effective atomic numbers approaching to that of human tissue $\left(Z_{\mathrm{eff}}=7.42\right)$ with very low hygroscopic nature [2-3]. Given that the glass TL dosimeters are resistant to water and therefore overcoming the adverse effect on the TL efficiency of the material that associated with non-radioactive relaxations during thermal stimulation [4].

In present study, it is intended to investigate new compound of calcium borate $\left(\mathrm{CaB}_{4} \mathrm{O}_{7}\right)$ glasses for application as thermoluminescence dosimeters (TLD). It is noted that calcium borate glasses have good chemical stability that of an important consideration for developing alternative forms of dosimeter [1, 5-8]. As reported elsewhere, the luminescence spectra and the glow peak in TLDs arise mainly from the signal in the doped core [21]. Rare earth elements as dopant in silica materials have gained much interest of many researchers as a result of $4 \mathrm{f}$ electronic configuration of rare earth in various glass matrixes and therefore leads to emission of ultraviolet and infrared [9], a matter which can be used to great benefit of radiation dosimetry system. The work presented herein makes use of the TL signal stored in rare earth based $\mathrm{Dy}_{2} \mathrm{O}_{3}$ as dopant in the calcium borate glass subjected to ionising radiation, offering an excellent TL yield and dose sensitivity [10]. The latter is considerably enhanced by the presence of structural defects in the material that have been created by the doping process.

\section{Materials and Methods}

A total of six glass samples were prepared from high grade purity chemical substances in the form of powder using conventional melt quenching method. The chemical compounds used in this work were $\mathrm{B}_{2} \mathrm{O}_{3}\left(69.6217 \mathrm{gmol}^{-1}\right), \mathrm{CaCO}_{3}\left(56.08\right.$ gmol $\left.^{-1}\right)$ and $\mathrm{Dy}_{2} \mathrm{O}_{3}(372.99$ gmol $^{-1}$ ) with $99.5 \%, 99.9 \%$ and $99.9 \%$ purity, respectively. In order to obtain $30 \mathrm{CaO}-(70-x)$ $\mathrm{B}_{2} \mathrm{O}_{3}$ doped with Dy $(0 \leq x \leq 0.4) \mathrm{mol} \%$ glass sample, the chemicals were weighted using an analytical balance and subseqeuntly mixed in alumina crucible. The glasses were melted in an electric furnace at $1200^{\circ} \mathrm{C}$ for 30 minutes (later being called as melt). The glasses were quenched by pouring out the melt on a flat metal plate and pressed by different metal plate with thickness of $1.5-2 \mathrm{~mm}$. The samples were then annealed for 2 hours at $300^{\circ} \mathrm{C}$ 
before being cooled at room temperature. The above steps were repeated for preparing other samples. Table 1 shows the details of the samples prepared.

Table 1 Details of the samples.

\begin{tabular}{|c|c|c|c|c|}
\hline $\begin{array}{c}\text { Sample } \\
\text { No }\end{array}$ & Remark $^{\text {a }}$ & \multicolumn{3}{|c|}{ Nominal Composition (mol \%) } \\
\hline S1 & Colorless glass & $\mathrm{H}_{3} \mathrm{BO}_{3}$ & $\mathrm{CaCO}_{3}$ & $\mathrm{Dy}_{2} \mathrm{O}_{3}$ \\
\hline S2 & Colorless glass & 70 & 30 & 0.0 \\
\hline S3 & Colorless glass & 69.95 & 30 & 0.05 \\
\hline S4 & Colorless glass & 69.9 & 30 & 0.1 \\
\hline S5 & Colorless glass & 69.7 & 30 & 0.3 \\
\hline S6 & Colorless glass & 69.6 & 30 & 0.4 \\
\hline
\end{tabular}

${ }^{\mathrm{a}}$ Visual inspection

The vitreous phase of the samples was characterised through X-ray diffraction (XRD) (Siemens D5000, Canada) technique. It is equipped with diffraction software analysis of $\mathrm{Cu} \mathrm{K}-\alpha$ radiation, operating at $40 \mathrm{kV}, 30 \mathrm{~mA}$ and Bragg-Brantano geometry at room temperature. Energy dispersive X-ray(EDXS) analysis (model JSM-6701, UK Company) was performed to measure the elemental composition of the glass samples investigated herein. Effective atomic number $\left(Z_{e f f}\right)$ results were determined by using the experimental values of weight fraction and compared to the theoretical values.

The glass samples were exposed to $6 \mathrm{MV}$ photon, use being made of linear accelerator (LINAC) Primus Multileaf Collimator 3339 MLC located at the Department of Radiotherapy and Oncology, Hospital Sultan Ismail in Johor Bahru. The photon irradiation was performed in the range of doses of $0.5 \mathrm{~Gy}$ to $4.0 \mathrm{~Gy}$ with dose rate of 200 $\mathrm{MU} / \mathrm{min}$. During irradiation, a bolus material was placed on top of the perspex to modulate the range of dose from external beam of radiation. The source to sample distance (SSD) was set at $100 \mathrm{~cm}$, with a field size of $15 \times 15 \mathrm{~cm}^{2}$. In all cases, the fibres were placed at the centre of the field. The glass samples were read 24 hours after irradiation, this would reduce the effect of spurious thermoluminescence signals. Once the samples rested for 24 hours, the TL glow curve measurement were carried out using a TLD reader (model 4500, Harshaw Chemical Company USA) provided by Nuclear Laboratory, Department Physics, Faculty of Science, Universiti Teknologi Malaysia (UTM). During readout, the heating rate used was constant at $10^{\circ} \mathrm{C} \mathrm{s}^{-1}$ and a continuous flux of $\mathrm{N}_{2}$ is supplied to reduce chemiluminescence in the heated samples. 


\section{Results and discussion}

\subsection{X-ray diffraction (XRD) analysis}

The XRD spectra of the samples of various Dy dopant concentrations is illustrated in Fig. 1. According to XRD data, it was confirm that the samples revealed bands without any discrete or continuous sharp peaks which indicated the amorphous character of the samples. This patterns were coincident with the card reported by the joint committee on JCPDS no: 76-0640.

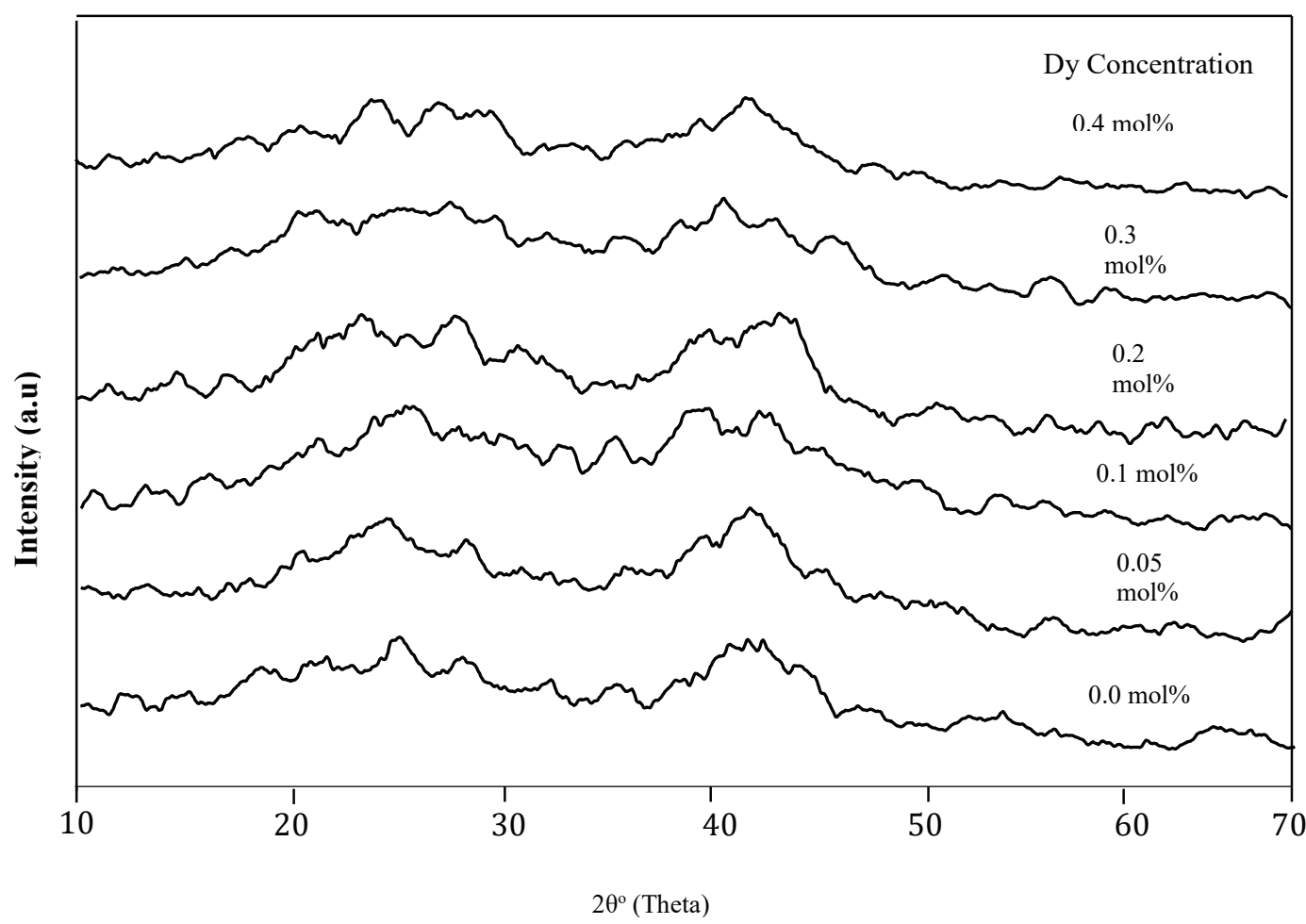

Fig. 1. The X-Ray diffraction spectra for Dy- doped and undoped glass samples. The dopant concentrations of Dy are labelled on the right hand side of the figure.

\subsection{Thermoluminescence (TL) Properties}

\subsubsection{Optimum dopant concentration of $\mathrm{Dy}_{2} \mathrm{O}_{3}$}

In this research, 30CaO-(70-x) $\mathrm{B}_{2} \mathrm{O}_{3}$ glass system has been doped with $0.1,0.2,0.3$, and $0.4 \mathrm{~mol} \%$ dysprosium (Dy) and irradiated at $6 \mathrm{MV}$ photon with an entrance dose of $4 \mathrm{~Gy}$. A graphical representation of the total number of counts recorded against temperature is 
as seen in Fig 2. A typical pattern for the glow curve obtained from the glass samples are a single broad peak, being characteristic of amorphouse media and does not change appreciably depending upon the concentrations. After the irradiation process, it was found that $0.30 \mathrm{~mol} \%$ Dy-doped calcium borate glass sample resulted highest TL response, being selected for subsequent measurements in investigating the response of the sample for different dose ranges, sensitivity, fading and reproducibility studies. It is also apparent that the glow peak of undoped calcium borate glass exhibits at $267^{\circ} \mathrm{C}$, being significantly elevated as the dopant concentration increased at $286^{\circ} \mathrm{C}$, in particular, $0.3 \mathrm{~mol} \%$ of Dydoped glass sample. It might be expected that the TL intensity will increase with dopant concentration, the number of electron traps and recombination centres increasing with dopant concentration, however, beyond an optimised concentration (nominal $0.30 \mathrm{~mol} \%$ ), the TL intensity of the samples actually decreases. This occurs because the distance between traps reduces as the number of traps and recombination centres increases, raising the probability for the light emitted from one recombination process to be absorbed by an electron in another trap. This phenomenon is called self-absorption. Moreover, the well known concentration quenching (CQ) effect have also attributed to this behaviour, which theoretically treated by Johnson and Williams (1950) [11] and later on modified by Ewles and Lee (1953) [12].

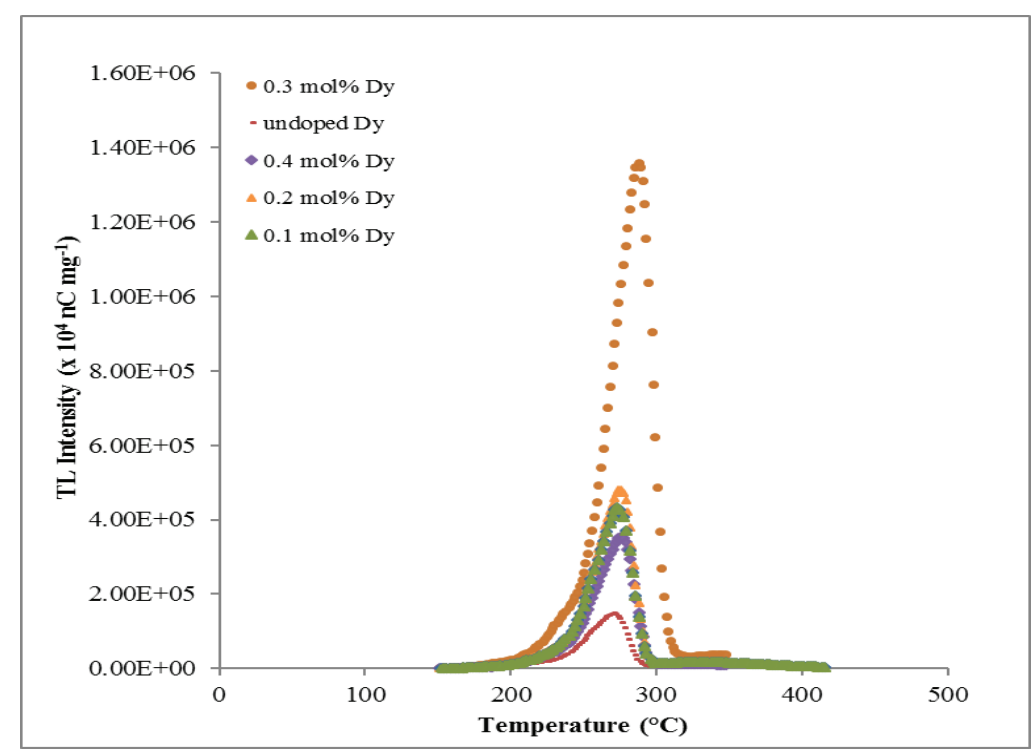

Fig. 2. Glow curves for different mol (\%) dopant concentration. 


\subsubsection{Optimum Annealing Temperature}

To investigate suitable annealing temperature for the selected calcium borate glass (nominal $0.30 \mathrm{~mol} \%$ of Dy-doped), four different annealing temperatures were tested, performing at $100,200,300$ and $400{ }^{\circ} \mathrm{C}$ for a period of 1 hour and in all cases irradiated by megavoltage photon beams of $6 \mathrm{MV}$ at a dose of $4 \mathrm{~Gy}$. Annealing process is crucial before making any irradiations and subsequent TL measurements in prior to achieve highest reproducibility for both background and TL signal. According to Prokic [13], this process also allows to eliminate the effect of previous irradiation. The TL intensity of the $0.3 \mathrm{~mol} \%$ Dy-doped glass sample against annealing temperature was measured and the summary results are shown in Fig. 3. In present study, each data point was obtained by taking an average of three individual measurements in order to plot the standard deviation against the annealing temperature. TL intensity with lowest standard deviation of the annealing temperature was found to be at $300^{\circ} \mathrm{C}$, thus selected for further $\mathrm{TL}$ characteristic studies.

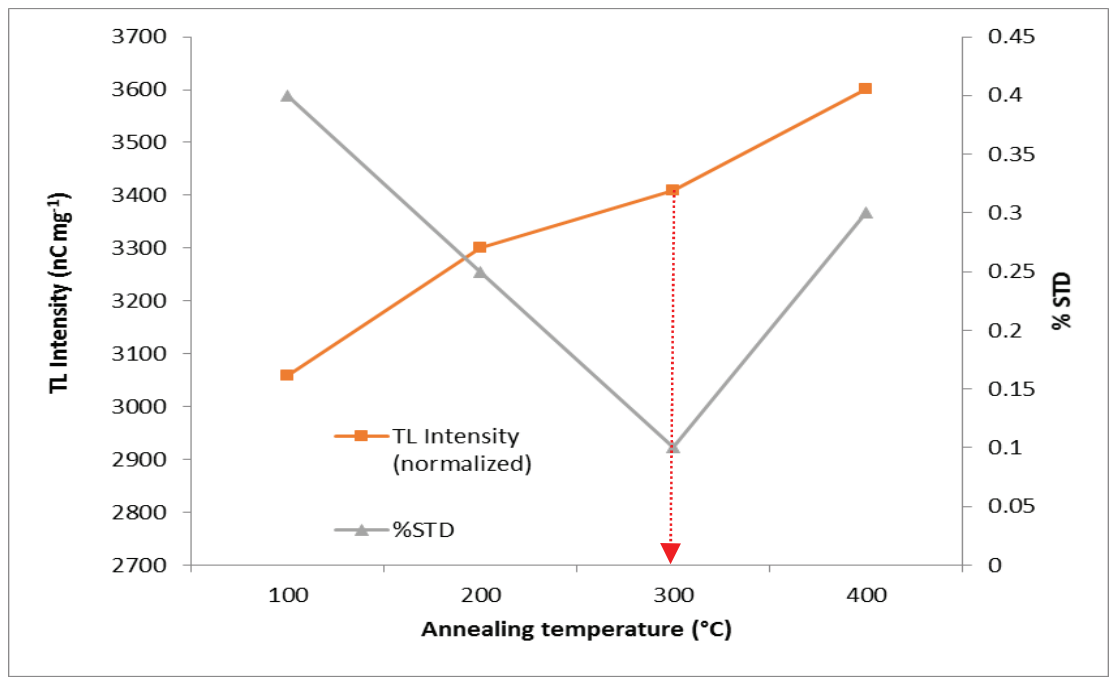

Fig. 3. The TL response and the corresponding standard deviation as a function of the annealing temperature. 


\subsubsection{Optimum Heating Rate}

It is important in use of the calcium borate glass sample that heating rate be characterised. The heating rate is a dynamic parameter which influences the characteristics of TL glow curve. As the heating rate increases the peak of glow curve will shifts to higher temperatures and the TL intensity measured will be decreased [14-15]. After exposure to $6 \mathrm{MV}$ photon of $4 \mathrm{~Gy}$ dose, the glass samples were readout at five different heating rates of 2, 5, 10, 12 and $15{ }^{\circ} \mathrm{C} \mathrm{s}^{-1}$. The optimum heating rate is obtained at $10{ }^{\circ} \mathrm{C} \mathrm{s}^{-1}$, considering the highest TL intensity with lowest standard deviation (see Fig. 4).

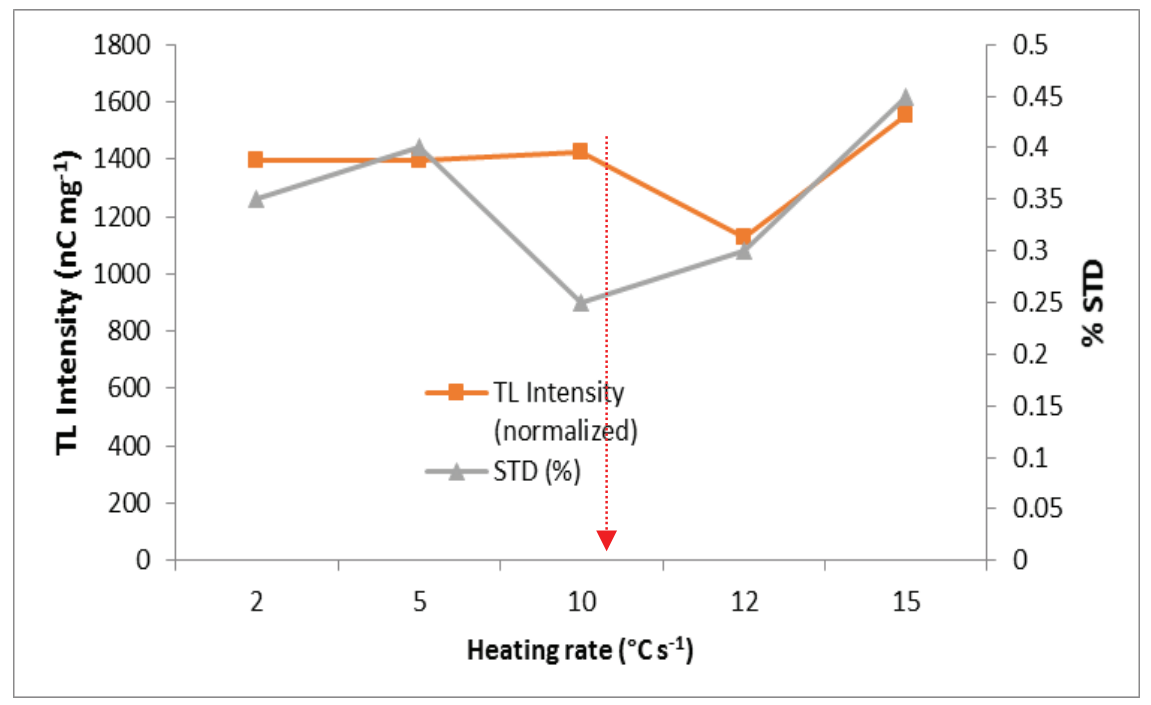

Fig. 4. TL response (normalized to unit mass) and the corresponding standard deviation as a function of the heating rate.

\subsubsection{Glow Curve}

Glow curve is obtained by measuring the luminescence and plot the results as a function of temperature. The relative amplitudes of the peaks indicate approximately the relative population of trapped electrons and trap depth, provided the heating rate is constant through the glow curve. Fig. 5 shows TL growth patterns of the prominent peaks of Dydoped calcium borate glass samples with increase of absorbed doses of 2, 3 and 4 Gy. It was observed that the glow peaks were gradually enhanced with increased in absorbed dose delivered to the glass sample. This can be explained by the number of filled traps, corresponding to the area under the glow peak, which in turn represented the amount of radiation energy deposited into the glass sample. These traps have consequently enhanced 
the TL intensity as a result of extrinsic doping of Dy, causing the glow peak shifted to higher temperature from $301.65^{\circ} \mathrm{C}$ to $309.94^{\circ} \mathrm{C}$ with respect to increment in absorbed dose. This behaviour is caused by releasing the deeper traps of the charge carriers in glass host so in principle, the concentration and storage capacity of these traps can provide a medium suitable for dosimetric application [16].

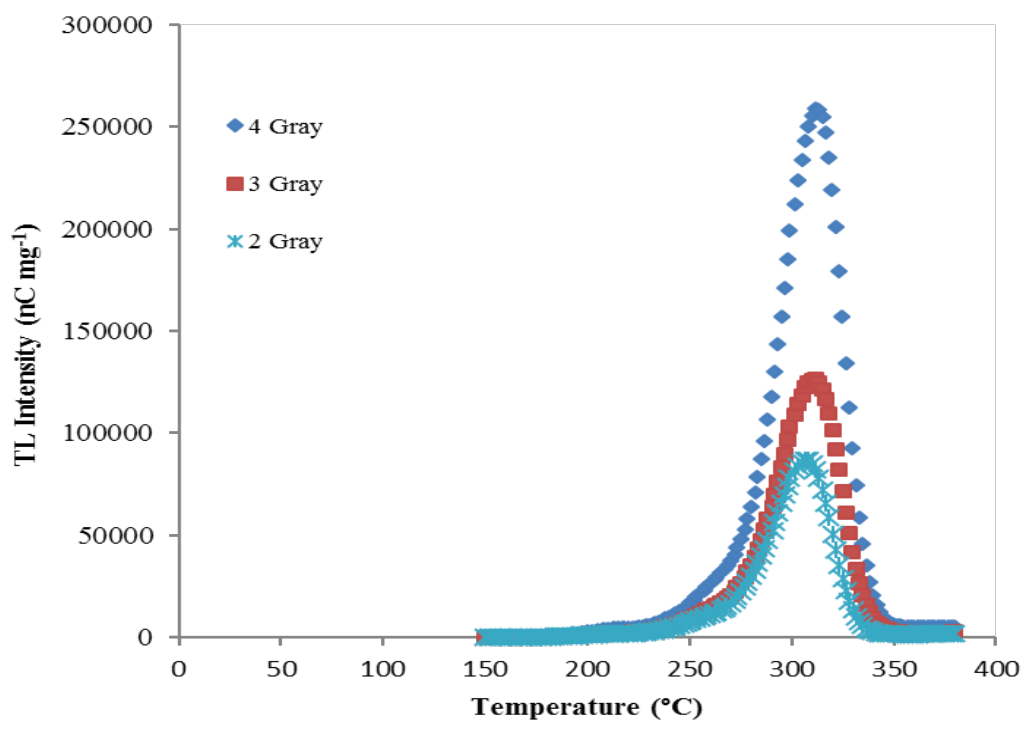

Fig. 5. Glow curve of $0.3 \mathrm{~mol} \%$ dysprosium doped calcium borate glass at different doses of photon irradiation.

\subsubsection{Linear Dose Response}

One of the important characteristics to assess the performance of dosimeters is through the study of linearity. It is desirable for TL materials to possess a linear relationship between the TL emission to the absorbed dose [17-20]. McKinlay (1981) has reported that the TL response of well-known phosphor TLDs, such as TLD-100 is usually, but not exclusively linear at low absorbed dose values, becoming supralinear and finally saturating at higher values. In this work the linearity for TLD-100, Dy-doped and undoped calcium borate glass samples subjected to $6 \mathrm{MV}$ and $10 \mathrm{MV}$ photons irradiations for a wide dose range (0.5 Gy - 4 Gy) were examined. Figure 6 shows the TL-dose relationship for each sample. Each data point represents the average of three individual glass sample readings together with the standard error of the mean. The increase in TL 
yield with dose remains linear over a wide range of values for all types of samples.. However, both glass samples produce lower TL response compared to that of TLD-100. A regression coefficient $\left(R^{2}\right)$ is another indication for linearity between dose and TL response. The solid lines are least square fits to the data, obtaining correlation coefficients of 0.9916, 0.9831 and 0.5285, respectively for TLD-100, Dy-doped and undoped glass samples. It is evident that the Dy-doped glass samples provide the basis for sensitive dosimetry throughout this range to that undoped glass sample, the TL intensity for the irradiation conditions increasing by $5 \%$ per additional 1 Gy of dose delivered.

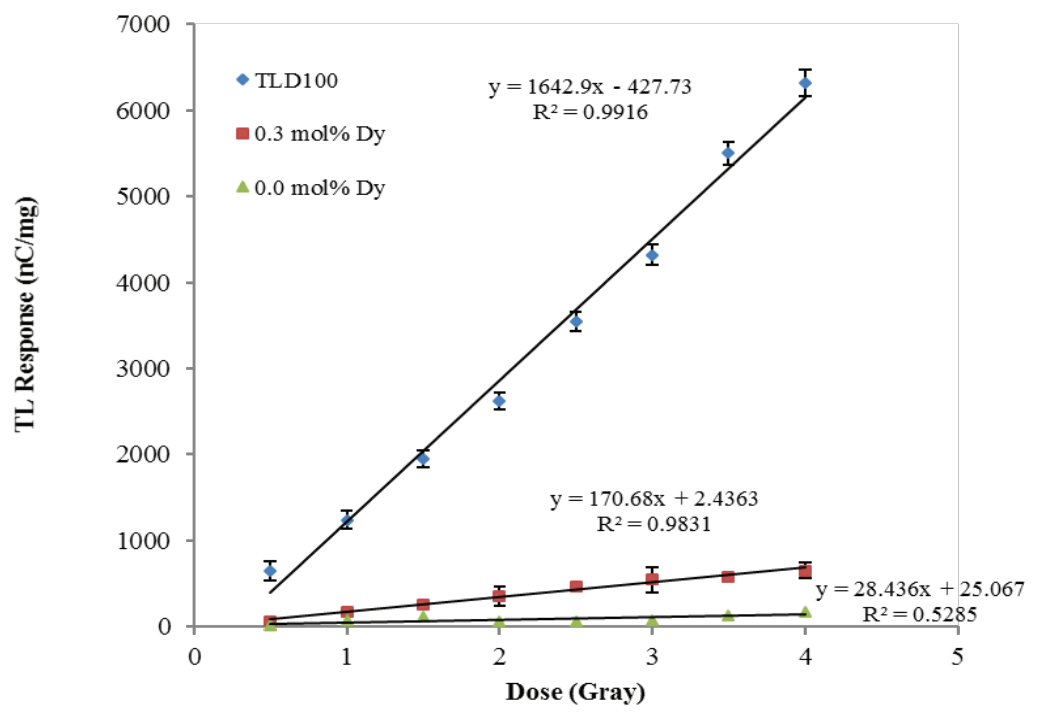

Fig. 6. The dose response for $0.3 \mathrm{~mol} \%$ Dy-doped and undoped calcium borate glass samples, in comparison with TLD-100 irradiated to a dose of 0.5 Gy to 4 Gy with MV photon beams of $6 \mathrm{MV}$.

\subsubsection{Fading}

Fading is the loss of stored thermoluminescene signals and depends largely upon the depth of traps and the storage temperatures of the TL materials. In general, if the TL signal from TLD sample is found to be unstable over the time after exposure to radiation, the signal is said to have faded. Note that fading can be affected by the heat treatment applied during annealing, readout procedures and exposure to visibile radiation and ultraviolet radiation. In present study, the fading effect of $0.3 \mathrm{~mol} \%$ Dy-doped glass sample was observed over a period of 60 days in order to understand the loss of TL response post irradiation. The percentage losses of TL signals can be obtained from equation 3.1 below (Suhairul, 2009): 
Percentage loss of TL sign

$$
=\frac{T L \text { response for } 1 \text { st day-TL response for last day }}{T L \text { response for } 1 \text { st day }}
$$

The fading effect of Dy-doped calcium borate glass, undoped calcium borate glass and TLD-100 over a period of 60 days storage time for photon beam irradiations of $6 \mathrm{MV}$ are demonstrated in Fig. 8, and 10, respectively. After 60 days, the average results are tabulated in Table 2. TLD-100 shows minimal loss in TL intensity of $8.7 \%$ followed by Dy-doped of $13.97 \%$ and undoped sample was observed to have maximum fading of $53.96 \%$ after 60 days. Table 3 shows different type of TLD with their own thermal fading.

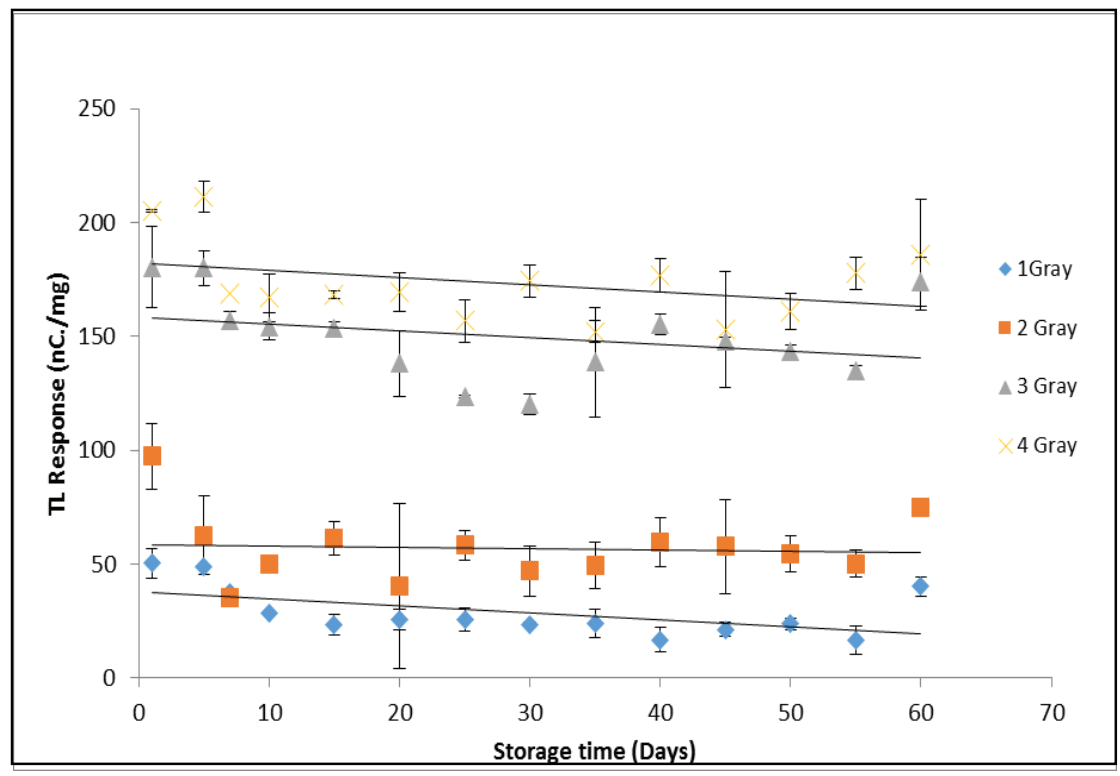

Fig.8 60 days variations of the TL response of the $0.3 \mathrm{~mol} \%$ dy doped calcium borate glass 


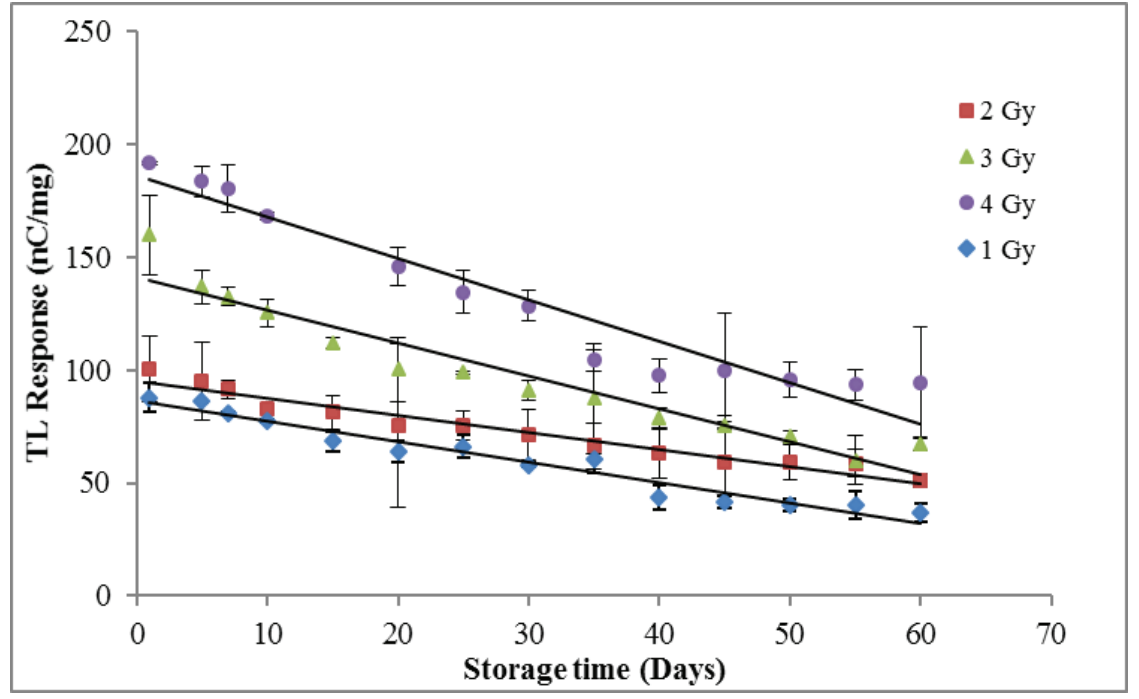

Fig. 960 days variations of the TL response of the undoped calcium borate glass

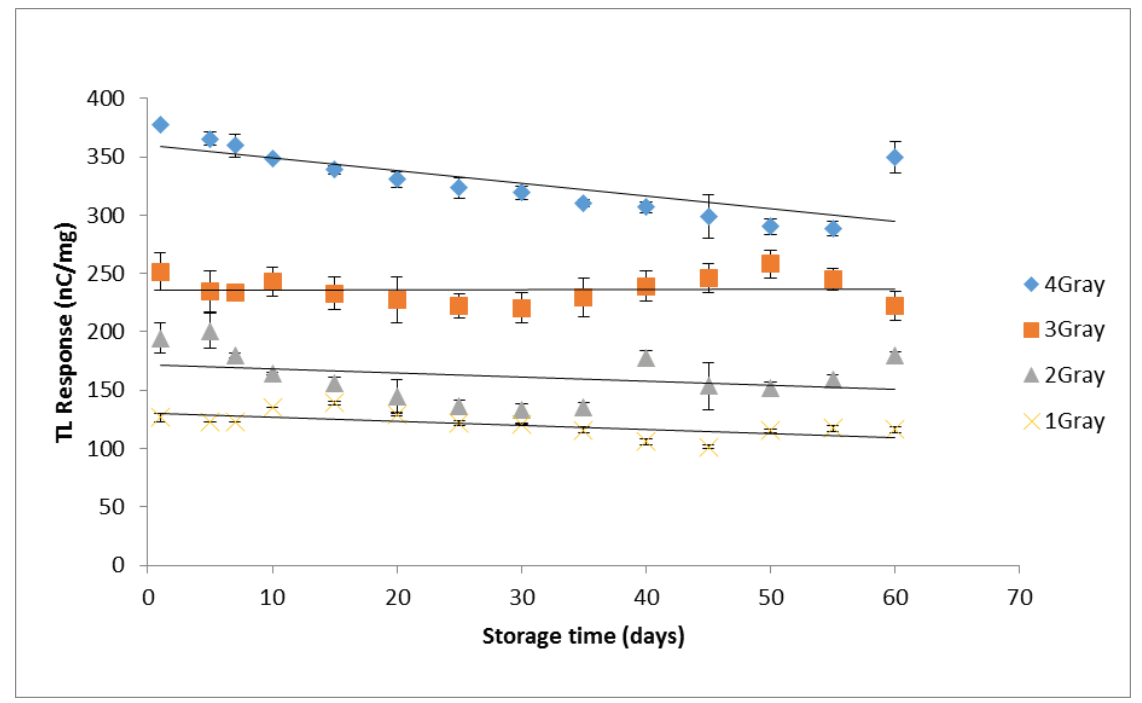

Fig. 10 The fading of TLD-100 for $10 \mathrm{MV}$ photon irradiation

Table 2 Summary of percentage loss of TL signal (due to fading) over the first 24 hours postirradiation for various TL materials.

\begin{tabular}{|c|c|c|c|c|c|}
\hline \multirow{2}{*}{ TL Materials } & \multicolumn{4}{|c|}{ Dose (Gray) } & \multirow{2}{*}{ Average } \\
\hline & 1 & 2 & 3 & 4 & \\
\hline Calcium Borate: Dy & 19.97 & 23.19 & 3.45 & 9.28 & 13.97 \\
\hline Undoped Calcium Borate & 58.15 & 49.08 & 58.04 & 50.58 & 53.96 \\
\hline LiF: Mg.Ti (TLD-100) & 8.13 & 7.66 & 11.64 & 7.39 & 8.70 \\
\hline
\end{tabular}


Table 3: Fade rates for some commercial TLD materials

\begin{tabular}{ccc}
\hline TLD Dosimeter & TLD Materials & Thermal Fading \\
\hline TLD 100 & $\mathrm{LiF}: \mathrm{Mg}, \mathrm{Ti}$ & $5-10 \%$ per year \\
TLD 200 & $\mathrm{CaF}_{2}: \mathrm{Dy}$ & $16 \%$ in two weeks \\
TLD 400 & $\mathrm{CaF}_{2}: \mathrm{Mn}$ & $15 \%$ in three months \\
TLD 500 & $\mathrm{Al}_{2} \mathrm{O}_{3}: \mathrm{C}$ & $3 \%$ per year \\
TLD 600 & ${ }^{6} \mathrm{LiF}_{\mathrm{Mg}}, \mathrm{Ti}$ & $5 \%$ per year \\
TLD 700 & $\mathrm{LiF}_{\mathrm{Mg}, \mathrm{Ti}}$ & $5 \%$ per year \\
TLD 800 & $\mathrm{Li}_{2} \mathrm{~B} 4 \mathrm{O}_{7}: \mathrm{Mn}$ & $5 \%$ in three months \\
TLD 900 & $\mathrm{CaSO}_{4}: \mathrm{Dy}$ & $8 \%$ in six months \\
\hline
\end{tabular}

\subsubsection{Sensitivity}

According to Furetta, 2003 [23], sensitivity of TLD can be defined as TL response (in reader unit) per unit of dose and unit of mass of the sample. It also can be expressed following equation;

$$
S=\frac{T L}{D \cdot m}
$$

where TL is the thermoluminescence response measured by the TLD reader, $D$ is deposited dose and $m$, mass of the sample. Sensitivity also depends upon the readout system used in the measurement, for instance, heating rate and light detection system. Table 3 shows the average ratio of sensitivity for TLD-100, Dy-doped and undoped calcium borate glass sample subjected to $10 \mathrm{MV}$ and $6 \mathrm{MV}$ photon irradiations. Comparison has been made with TLD-100, producing greater sensitivity and outperform other materials. Taking TLD-100 as the benchmark, Dy-doped calcium borate glass exhibits lower sensitivity of some 5 times to that TLD-100. However, as expected, the doping presence has produce a significant sensitivity to that undoped glass sample of some 3 times. The significant energy dependency of the doped calcium borate glass in the MV range point to a potential for energy discrimination of the incident photons if these glass samples are used in conjunction with TLD-100. 
Table 4 TL sensitivity (TL yield.mg ${ }^{-1}$.Gy ${ }^{-1}$ ) for TLD-100, Dy- doped and undoped Calcium Borate glass sample for $6 \mathrm{MV}$ and $10 \mathrm{MV}$ photon irradiations

\begin{tabular}{c|c|c|c|c|c|c}
\hline \multirow{2}{*}{ Materials } & Energy/Dose & $\mathbf{1}$ Gy & $\mathbf{2}$ Gy & $\mathbf{3 ~ G y}$ & $\mathbf{4}$ Gy & Average \\
\hline \multirow{2}{*}{ LiF: Mg.Ti (TLD-100) } & $\mathbf{1 0} \mathbf{~ M V}$ & 79.8 & 93.5 & 102.3 & 206.3 & 120.475 \\
\cline { 2 - 7 } & $\mathbf{6 ~ M V}$ & 51.2 & 54.2 & 59.6 & 65.2 & 57.5 \\
\hline \multirow{2}{*}{ Calcium Borate: Dy } & $\mathbf{1 0} \mathbf{~ M V}$ & 21 & 26.5 & 31.5 & 43.5 & 30.625 \\
\cline { 2 - 7 } & $\mathbf{6 ~ M V}$ & 35.2 & 28.1 & 42.0 & 35.9 & 35.3 \\
\hline \multirow{2}{*}{ Calcium Borate } & $\mathbf{1 0} \mathbf{~ M V}$ & 8.1 & 5.3 & 5.1 & 4.9 & 5.85 \\
\cline { 2 - 7 } & $\mathbf{6 ~ M V}$ & 2.3 & 1.6 & 2.0 & 2.0 & 2.0 \\
\hline
\end{tabular}

\subsubsection{Effective atomic number, $Z_{\text {eff }}$}

The response of a TL material to $\mathrm{x}$ - and gamma rays detection depends on the atomic number of its constituents as in [18]. The effective atomic number, $Z_{\text {eff }}$ of an ideal dosimeter is very important in radiotheraphy for calculating the treatment dose in cancer patients [16], defining an equivalent value for mixtures and compounds that offers $Z_{\text {eff }}$ equal to or close to the composition of human biological tissue. The $Z_{\text {eff }}$ of glass sample used herein was measured through the strength of different interaction probabilities or cross section between gamma rays and the studied materials [24] prior obtaining its expected TL response at different energies, use being made of XCOM software method. $30 \mathrm{CaO}-(70-x) \mathrm{B}_{2} \mathrm{O}_{3}$ glass system (where $x=0,0.05,0.1,0.2,0.3,0.4$ and $0.5 \mathrm{~mol} \%$ of dopant concentration) was initially converted to weight fraction and the $Z_{\text {eff }}$ value a found to be in the range of 12.14 to 13.22 , specifically for $x=2.94 \mathrm{~mol} \%$ and $x=3.5 \mathrm{~mol} \%$, respectively. Also calculated the percentage difference to be $8 \%$ with average of 12.68 . The variation of the mean values of $Z_{\text {eff }}$ for the present Dy doped glass system is shown in Fig 11. It is apparent that $Z_{\text {eff }}$ increases with increasing Dy concentration and the values ranging from 12.68 to 15.13 . This variation is represented by an excellent correlation coefficient, $R^{2}=0.98$. These results indicate that Dy-doped calcium are not tissue equivalent (value of $Z_{\text {eff }}$ in soft tissue is 7.5) and as such the assessment of dose deposition in tissue would need to be corrected and calibrated. However, the effective atomic number is not greatly different to that of the bone, 13.8. 


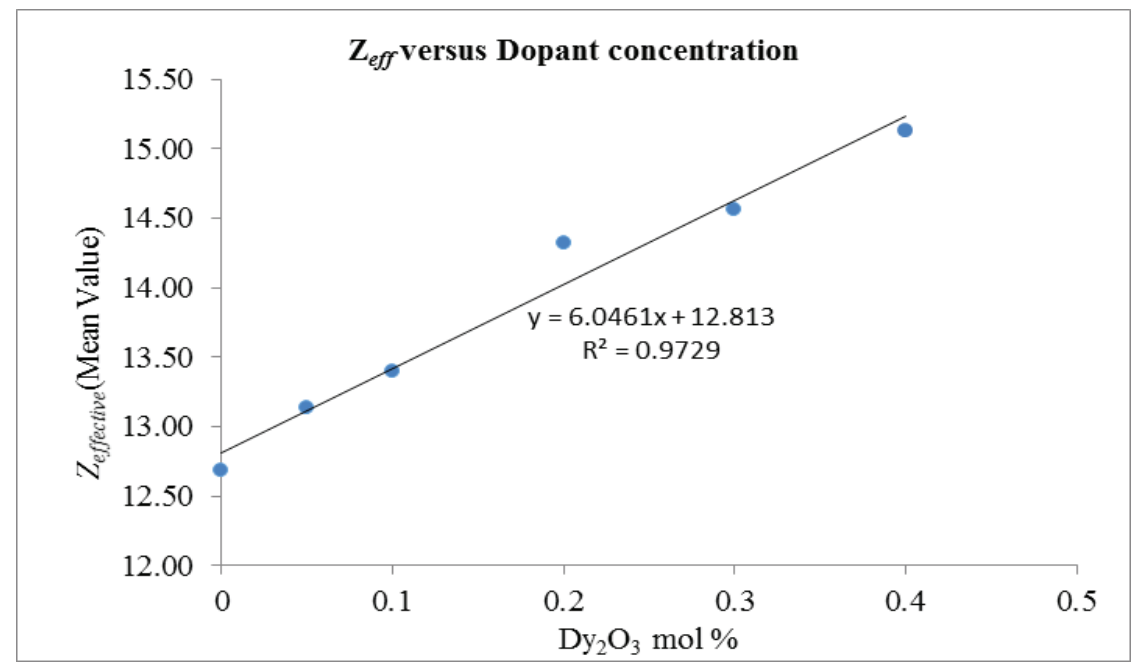

Fig. 11. The effective atomic number of $30 \mathrm{CaO}-(70-x) \mathrm{B}_{2} \mathrm{O}_{3}$ glass system (where $x=0,0.1,0.2,0.3$ and $0.4 \mathrm{~mol} \%$ of dopant concentrations)

\section{Conclusion}

The thermoluminescence dosimetric properties, incorporating glow curve structure, linearity, fading, reproducibility and effective atomic number were investigated for $30 \mathrm{CaO}-(70-\mathrm{x}) \mathrm{B}_{2} \mathrm{O}_{3}: \mathrm{xDy}_{2} \mathrm{O}_{3}$ glass system. The optimum concentration for TL response of calcium borate doped with $\mathrm{Dy}_{2} \mathrm{O}_{3}$ was found to be 0.3 mol\%, producing high TL intensity at temperature peak of $286^{\circ} \mathrm{C}$. In addition, annealing temperature that offer greater TL intensity and glow peak for the glass sample tested herein was measured to be $300^{\circ} \mathrm{C}$, with heating rate of $10^{\circ} \mathrm{Cs}^{-1}$. Through the current study, the dosimetry of Dydoped calcium borate glass have been shown to posses considerable characteristics, including good TL-dose linearity, sensitivity and reproducibility. TL glow curve for studied glass exhibited single, broad curve and has maximum intensity of $286^{\circ} \mathrm{C}$. Moreover, $30 \mathrm{CaO}-(70-\mathrm{x}) \mathrm{B}_{2} \mathrm{O}_{3}: \mathrm{xDy}_{2} \mathrm{O}_{3}$ glass offers many other advantages over conventional dosimetry systems, including the calcified tissue equivalence of the dosimetric material. The value of effective atomic number, $\mathrm{Z}_{\text {eff }}$ is calculated to be 13.56 being close to that of bone. The outcome of the current research is expected to be useful in developing and characterising tailor-made doped borate glass modified with calcium as new potential TLD materials for fraction dose estimation in bone cancer treatment. 


\section{Acknowledgement}

The authors would like to thank the Ministry of Education (MOE) of Malaysia and Universiti Teknologi Malaysia for financial support through research grant No. $03 \mathrm{H} 28$ and the facilities.

\section{References}

1. M. Satiago et al Phys Status Solid A, 2285 (2001)

2. Y. Fukuda, T. Okuno., N. Takeuchi. Thermoluminescence of Borate Glass Containing Copper. Rad. Protectn Dosimentry, 6 309-312

3. S.S. Rojas., K. Yukimitu, A. S. S. De Camargo., L. A. O. Nunes., \& A. C. Hernandes, Undoped and calcium doped borate glass system for thermoluminescent dosimeter. Journal of non-crystalline solids, 32, 3608-3612 (2006)

4. S.W.S McKeever, Thermoluminescence of Solid, Cambridge University Press (1985)

5. C. K. Sangeeta., S.C. Sabharwal, J. Lumin. 104267 (2003).

6. C. K. Sangeeta., S.C. Sabharwal, J. Lumin. 10969 (2004).

7. Y. Fukuda, A. Tomita, N. Takeuchi, Phy. Status Solid A 85141 (1984).

8. Y. Fukuda, A. Tomita, N. Takeuchi, Phy. Status Solid A 99135 (1987).

9. M. Ferhi, K. Horchani-Naifer, and M. Ferid, Combustion synthesis and luminescence properties of $\mathrm{LaPO}_{4}$ : Eu (5\%). Journal of Rare Earth. 27 182-187 (2009).

10. H. Ohtaki, Y. Fukuda, \& N. Takeuchi, Thermoluminescence in calcium phosphate doped with $\mathrm{Dy}_{2} \mathrm{O}_{3}$. Radiation Protection Dosimetry, 47, 119-122 (1993).

11. Johnson, P. D., \& Williams, F. E. (1950). The interpretation of the dependence of luminescent efficiency on activator concentration. The Journal of Chemical Physics, 18(11), 1477-1483 (1950).

12. Ewles, J., Lee, N,. Studies on the concept of large activator centers in crystal phosphors. J. Electrochem. Soc. 100, 392e398. (1953).

13. M. Prokic, Radiat. Meas. 33393 (2001). 
14. Mahesh, K., Weng, P. S., \& Furetta, C. Thermoluminescence in Solids and its Applications. Nuclear Technology Pub. (1989)

15. Gleiter, H. Nanocrystalline materials. In Advanced Structural and Functional Materials (pp. 1-37). Springer, Berlin, Heidelberg. (1991)

16. McKeever, S. W.Thermoluminescence of solids (Vol. 3). Cambridge University Press.(1988).

17. A. J. J. Bos, Theory of thermoluminescence. Radiat. Meas. 41, S45-S56 (2007).

18. A. J. J. Bos, High sensitivity thermoluminescence dosimetry. Nuclear Instruments and Methods in Physics Research Section B: Beam Interactions with Materials and Atoms, 1, 3-28 (2001).

19. G. Busuoli, General characteristics of TL materials. Applied thermoluminescence dosimetry: lectures of a course held at the Joint Research Centre, Ispra, 12, 1687 (1979).

20. McKinlay, Alastair F. "Thermoluminescence dosimetry." (1981).

21. Hashim, S., Bradley, D. A., Saripan, M. I., Ramli, A. T., \& Wagiran, H. The thermoluminescence response of doped $\mathrm{SiO} 2$ optical fibres subjected to fast neutrons. Applied Radiation and Isotopes, 68(4), 700-703 (2009).

22. Furetta, Claudio. "Handbook of Thermo." Luminescence (2003).

23. K. Mizuguchi, \& Y. Fukuda, Thermoluminescence and Thermally Stimulated Exoelectron Emission of Ca3 (PO4) 2: Dy and Ca3 (PO4) 2: Tm. Radiat. Prot. Dosim, 84, 301-305 (1999).

24. Hubbell, J.H. Review of photon interaction cross section data in medical and biological context. Phys Med. Biol. 44, R1-R22 (1999a). 